\title{
Transcriptome Changes in the Mink Uterus during Blastocyst Dormancy and Reactivation
}

\author{
Xinyan Cao ${ }^{1}$, Jiaping Zhao ${ }^{1}$, Yong Liu ${ }^{2}$, Hengxing Ba ${ }^{1} \oplus$, Haijun Wei ${ }^{1}$, Yufei Zhang ${ }^{1}$, \\ Guiwu Wang ${ }^{1}$, Bruce D. Murphy ${ }^{3, *}$ and Xiumei Xing ${ }^{1, *}$ \\ 1 Institute of Special Animal and Plant Sciences, Chinese Academy of Agricultural Sciences, \#4899 Juye Street, \\ Jingyue District, Changchun 130112,China; xinyan_99@163.com (X.C.); tcszjp@126.com (J.Z.); \\ Bahengxing@caas.cn (H.B.); weihaijun2005@sina.com (H.W.); Zhangyufei@caas.cn (Y.Z.); \\ wangguiwu2005@163.com (G.W.) \\ 2 Key Laboratory of Embryo Development and Reproductive Regulation of Anhui Province, \\ College of Biological and Food Engineering, Fuyang Teachers College, Fuyang 236000, China; \\ drliuyong@gmail.com \\ 3 Centre de Recherché en Reproduction et Fertilité, Faculté de Médicine Vétérinaire, Université de Montréal, \\ St-Hyacinthe, QC J2S 2M2, Canada \\ * Correspondence: d.murphy@umontreal.ca (B.D.M.); xingxiumei2004@126.com (X.X.)
}

Received: 14 March 2019; Accepted: 23 April 2019; Published: 28 April 2019

check for updates

\begin{abstract}
Embryo implantation in the mink follows the pattern of many carnivores, in that preimplantation embryo diapause occurs in every gestation. Details of the gene expression and regulatory networks that terminate embryo diapause remain poorly understood. Illumina RNA-Seq was used to analyze global gene expression changes in the mink uterus during embryo diapause and activation leading to implantation. More than 50 million high quality reads were generated, and assembled into 170,984 unigenes. A total of 1684 differential expressed genes (DEGs) in uteri with blastocysts in diapause were compared to the activated embryo group $(p<0.05)$. Among these transcripts, 1527 were annotated as known genes, including 963 up-regulated and 564 down-regulated genes. The gene ontology terms for the observed DEGs, included cellular communication, phosphatase activity, extracellular matrix and G-protein couple receptor activity. The KEGG pathways, including PI3K-Akt signaling pathway, focal adhesion and extracellular matrix (ECM)-receptor interactions were the most enriched. A protein-protein interaction (PPI) network was constructed, and hub nodes such as VEGFA, EGF, AKT, IGF1, PIK3C and CCND1 with high degrees of connectivity represent gene clusters expected to play an important role in embryo activation. These results provide novel information for understanding the molecular mechanisms of maternal regulation of embryo activation in mink.
\end{abstract}

Keywords: embryo diapauses; activated; RNA-seq; uterus; mink

\section{Introduction}

Embryo implantation is a dynamic process, that comprises periods of uterine pre-receptivity, receptivity and implantation phases, involving morphological and molecular changes in the endometrium. This process varies among mammals. Mink are within the subset of carnivores in which pre-implantation embryo diapause occurs in every gestation [1,2]. It is believed that the period of embryo arrest in the uterus is associated elevated embryonic mortality rates. Reciprocal embryo transfer between mink and the ferret, a related species exhibiting no embryo diapause, revealed that diapause is controlled primarily by the maternal uterine environment, rather than by the embryos [3]. When diapause embryos are co-cultured with endometrial epithelial and stromal cells, they show extended survival of the embryos in vitro and, in some cases, escape from their quiescent state [4]. The molecular changes in the uterus 
during implantation have been explored [5-7]. However, the precise factors and mechanisms by which the uterus activates the embryo from diapause remain to be elucidated.

Previous studies of differential gene expression in the uterus during reactivation of embryo development in mink were carried out using the suppressive subtractive hybridization (SSH) technique, generating a library of 123 differential expressed genes (DEGs) between uteri with blastocysts in diapause and uteri with reactivated blastocysts [7]. This method has a number of limitations, and does not to provide a comprehensive analysis of the global transcriptome. With the development of high-throughput mRNA sequencing technology (RNA-seq), Illumina platform has become the most used method, as it is an accurate tool for quantifying RNA abundance and diversity, and has the capacity to identify novel transcribed regions, splice isoforms and single nucleotide polymorphisms (SNPs). Indeed, a number of studies have employed the platform to understand the dynamics of gene expression during early embryonic development. For example, Zhang [8] using the RNA-Seq method, found that 3255 unigenes were differentially expressed between the receptive and pre-receptive endometria in dairy goats. In the porcine endometrium, Samborski [9] reported 2593 DEGs between pregnant and non-pregnant animals. Furthermore, differential gene function, multiple pathways and regulatory networks were also identified in these studies.

Prenatal mortality is a constraint on litter size in mink. It has been well demonstrated that embryonic losses occur during gestation, and it is believed that much of this mortality occurs during diapause in mink. It is estimated that approximately $60 \%$ of fertilized ova do not survive through gestation in this species [1,10]. A detailed investigation into global gene expression in the maternal uterine environment during the establishment of pregnancy will augment understanding of gene function and of the regulatory mechanisms that influence embryonic survival and implantation. This information will be valuable for the development of mitigation strategies to increase the frequency of successful pregnancy establishment and larger litters at parturition.

Here, we present a wide screen RNA analysis to characterize gene expression of uterine tissue during embryo diapause and reactivation. We adopted the Illumina sequencing approach to obtain a larger and more reliable transcriptomic dataset, to provide information on candidate regulatory factors, and illustrate intricate molecular regulatory networks and biological functions that characterize the uterine changes during the transition from diapause to embryo activation in the mink uterus.

\section{Results}

\subsection{Identification of Transcriptomic Differences}

This study used RNA-Seq to investigate the transcriptome changes of the uterus from diapause to the activation period of mink. RNA was purified from the uterus in diapause and activation phases with three biological replicates for each group. Sequencing of the libraries yielded more than 54.3 and 57.6 million quality reads for the diapause and activated group, respectively. After removing invalid reads, we acquired 52.1 and 55.3 million clean reads from each group, respectively. A total of 170,984 unigenes were obtained from clean reads using the optimized parameters.

A total of 1684 transcripts were identified to as being differentially expressed (based on log2 fold change, $p<0.05)$ in whole uterine horns between the diapause and activated groups. Among these transcripts, 1527 were annotated as known genes, thus approximately $10 \%$ of transcripts were unable to be annotated. Among the DEGs, 963 were significantly more abundant in the activated uterus ( 622 genes fold $>2$, and 167 genes fold $>1.5$ and simultaneously fold $<2$ ), while 564 genes were more abundant in diapause groups ( 445 genes fold $>2$, and 58 genes fold $>1.5$ and simultaneously fold $<2$ ) (Table 1). The top 20 most DEGs (highest $p$ value) in the activated uterus are presented in Table 2. 
Table 1. Number of differential expressed genes (DEGs) in uterus of diapause and 5 days after embryo activation.

\begin{tabular}{cccc}
\hline Comparison $^{\mathbf{a}}$ & ${\text { Fold }>\mathbf{2}^{\mathbf{b}}}$ & Fold $>\mathbf{1 . 5}^{\mathbf{c}}$ & $\boldsymbol{p}<\mathbf{0 . 0 5}^{\mathbf{d}}$ \\
\hline Activated $>$ Diapause & $622(738)$ & $167(178)$ & $963(1063)$ \\
Diapause $>$ Activated & $445(502)$ & $58(67)$ & $564(621)$ \\
All & $1067(1240)$ & $225(245)$ & $1527(1684)$ \\
\hline
\end{tabular}

${ }^{a}$ Gene expression changes. Activated $>$ Diapause indicates that expression levels in activated are higher than during diapause. Diapause $>$ Activated indicates that expression levels in activated are lower than diapause. ${ }^{b}$ Genes with at least a two-fold change in expression between activated and diapauses. Number in parentheses indicates total number of DEGs. ${ }^{c}$ Genes differential fold more than 1.5 , and simultaneously differential fold less than 2 between the activated and diapause group. Number in parentheses indicates total number of DEGs. ${ }^{d}$ Total number of differentially expressed annotated genes based on a $p$-value less than 0.05 ; number in parentheses indicates total number of DEGs.

Table 2. The top 20 most DEGs in the activated uterus compared with the diapause uterus $(p<0.05)$.

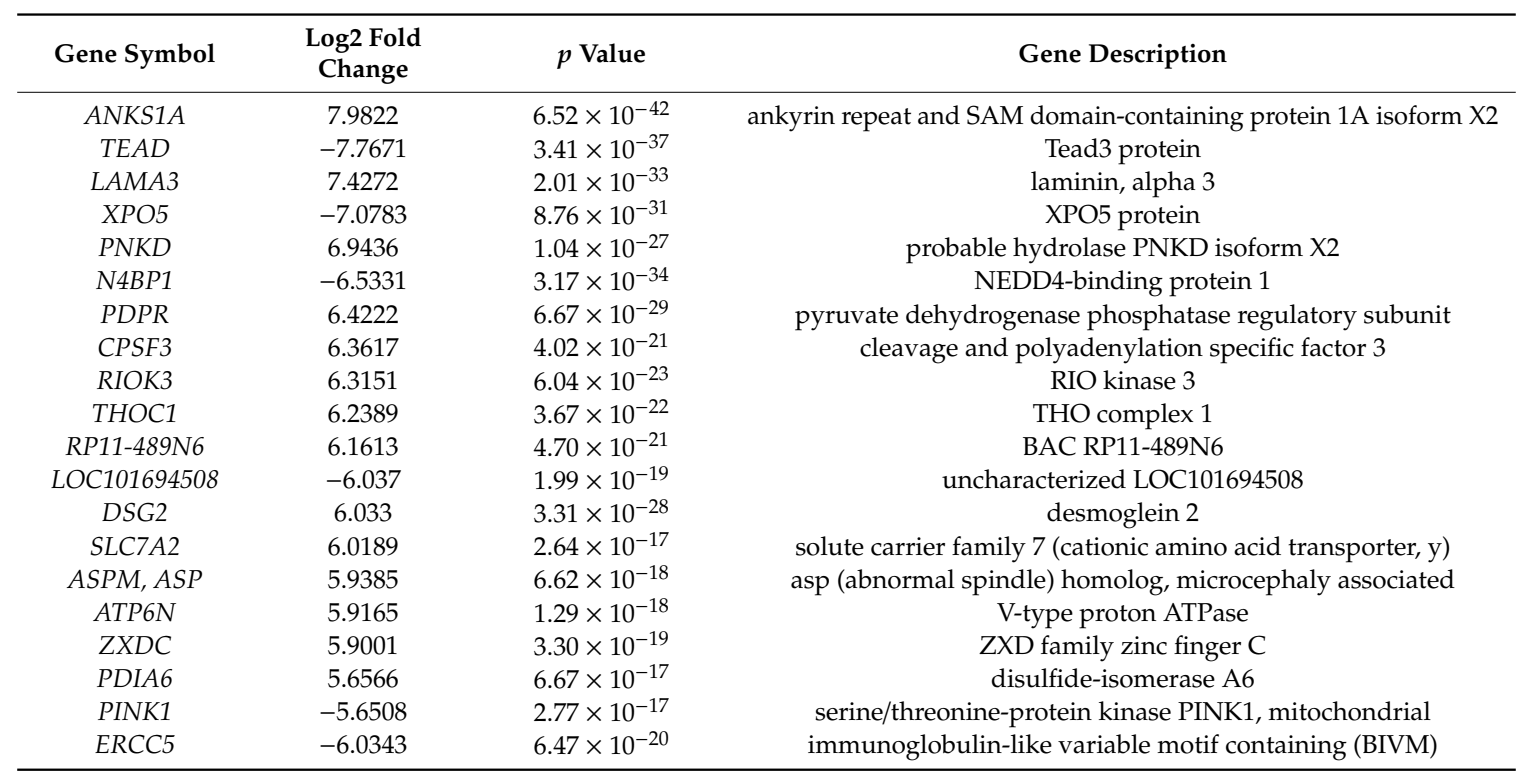

\subsection{Gene Ontology Analysis of the DEGs}

To gain insight into the biological functions that are regulated during embryo activation, we conducted a function enrichment analysis of DEGs based on gene ontology (GO). A total of $241 \mathrm{GO}$ terms were overrepresented between the activated and diapause uteri $(p<0.05)$. Of the $148 \mathrm{GO}$ terms that were identified in the biological process, the most significantly enriched terms were the xenobiotic metabolic process (20 genes), cellular response to stimulus (219 genes), cell communication (190 genes), signal transduction (186 genes), G-protein coupled receptor signaling pathway (42 genes), regulation of embryonic development ( 7 genes), vitamin metabolic process (24 genes), regulation of cell adhesion (18 genes), regulation of cell migration (32 genes), regulation of locomotion (8 genes) and immune response (20 genes). In the cellular compartment GO category, 17 terms were significantly enriched. The most significantly enriched GO terms were extracellular matrix ( 9 genes), extracellular region part (45 genes), collagen trimer ( 9 genes), membrane (318 genes), interleukin-1 receptor complex (1 genes) and MHC protein complex (5 genes). In the molecular function, phosphatase activity (38 genes), N,N-dimethylaniline monooxygenase activity ( 5 genes), G-protein coupled receptor activity (27 genes) and metallocarboxypeptidase activity (5 genes) were the most enrichment (Table 3 ). The most significantly enriched pathways were responsible for endometrial morphological changes and function involved in the extracellular matrix, cell migration and adhesion. Genes included laminin (LAMA1, 3, 5), collagen (COL1A1, COL4A, COL12A1, COL6A), ADAM metallopeptidase (ADAMTS9, ADAMTS12, ADAM33), tropomyosin (TPM1), osteonectin (SPARC, SPOCK) and thrombospondin (THBS1, THBS2). 
Table 3. Top 10 gene ontology (GO) terms and enriched genes in the activated uterus vs. the diapause uterus at $p<0.01$.

\begin{tabular}{|c|c|c|c|}
\hline Category & Terms & $p$ Value & Genes \\
\hline \multirow[t]{4}{*}{$\mathrm{BP}$} & Xenobiotic metabolic process & $2.98 \times 10^{-5}$ & 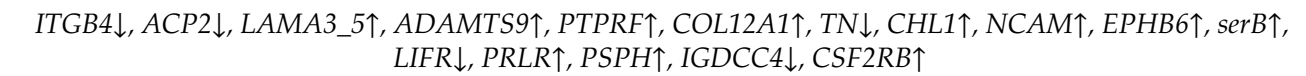 \\
\hline & Cell communication & $6.38 \times 10^{-5}$ & 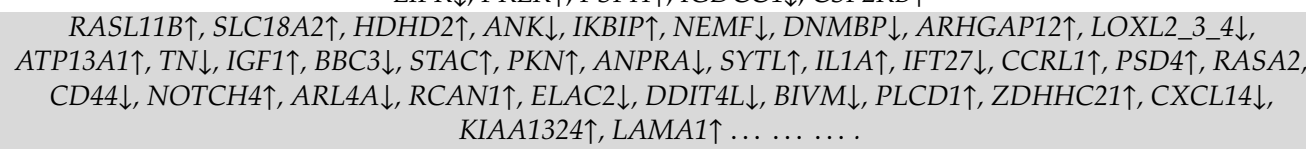 \\
\hline & Signal transduction & $7.08 \times 10^{-5}$ & 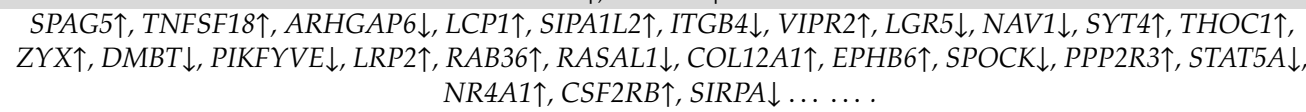 \\
\hline & Cellular response to stimulus & $9.02 \times 10^{-5}$ & 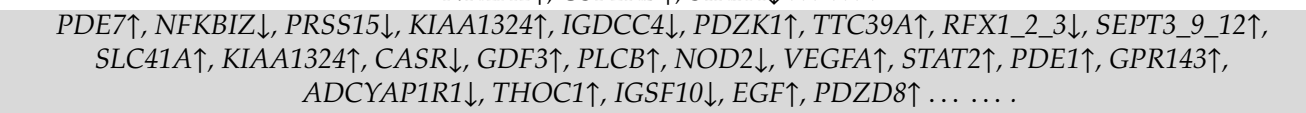 \\
\hline \multirow[t]{2}{*}{$\mathrm{CC}$} & Extracellular matrix & $7.05 \times 10^{-9}$ & 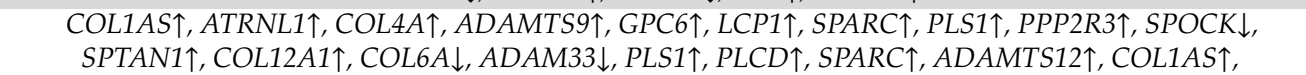 \\
\hline & Collagen trimer & $7.79 \times 10^{-5}$ & 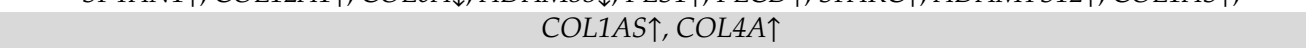 \\
\hline \multirow[t]{4}{*}{ MF } & Phosphatase activity & $8.98 \times 10^{-6}$ & $\begin{array}{c}P T P R F \uparrow, A R L 4 \downarrow, A L C A M \uparrow, A C P 2 \downarrow, E P H B 6 \uparrow, C P Z \uparrow, N C A M \uparrow, C O L 12 A 1 \uparrow, P T P 4 A \uparrow, S E R B \uparrow, C H L 1 \uparrow, \\
P H O S P H O 2 \uparrow, E P H B 6 \uparrow, D U S P \uparrow, P T P R R \uparrow, P R L R \uparrow, C S F 2 R B \uparrow, A D A M T S 9 \uparrow, C C B L \uparrow, I T G B 4 \downarrow, D C H S 1 \_2 \uparrow\end{array}$ \\
\hline & $\begin{array}{l}\mathrm{N}, \mathrm{N} \text {-dimethylaniline } \\
\text { monooxygenase activity }\end{array}$ & $4.28 \times 10^{-4}$ & - \\
\hline & $\begin{array}{l}\text { G-protein coupled receptor } \\
\text { activity }\end{array}$ & $4.42 \times 10^{-4}$ & 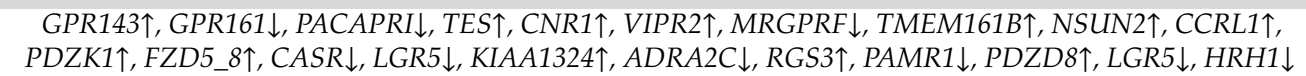 \\
\hline & $\begin{array}{l}\text { Metallocarboxypeptidase } \\
\text { activity }\end{array}$ & $7.08 \times 10^{-4}$ & $C P X M 1 \uparrow, C P Z \uparrow, C P N 1 \uparrow, C P X M 2 \uparrow$ \\
\hline
\end{tabular}




\subsection{KEGG Pathway Analysis of DEGs}

KEGG pathway enrichment analysis was performed on these DEGs and a cut-off criterion of $p<0.05$ was also used. A total of 18 enriched pathways were found between the activated and diapause groups. The classification indicated that the PI3K-Akt signaling pathway (Figure 1), focal adhesion, ECM-receptor interaction (Figure 2), cell adhesion molecules and protein digestion and absorption were highly enriched. The top 10 KEGG pathways are shown in Table 4 . The most significantly enriched pathways were those responsible for cell adhesion and those involved in extracellular matrix remodeling, highly enriched genes included CD44, LAMA1-5, ITGB4, ITGA5, ITGB8, COL4A, ITGAM and LAMC3. Genes in the pathways related to immune gene expression, such as COL1AS, COL6A, FGFR4, XPNPEP2, IL1A and MHC2 were likewise enriched.

The pituitary hormone, prolactin, has recently been shown to have direct effects on the mink uterus, acting through membrane receptors [2], promoting epithelial cell changes via janus kinase-2 signal transducer and activated PI3K-Akt signaling pathway (Figure 3). This pathway has been implicated in the regulation of cell survival, apoptosis, cell cycle progression, metabolism, and cell proliferation and growth. Genes enriched in this pathway include ELF5, PIK3C, AKT, CYP17A, PRLR, STAT5A and CCND1 (Table 4).

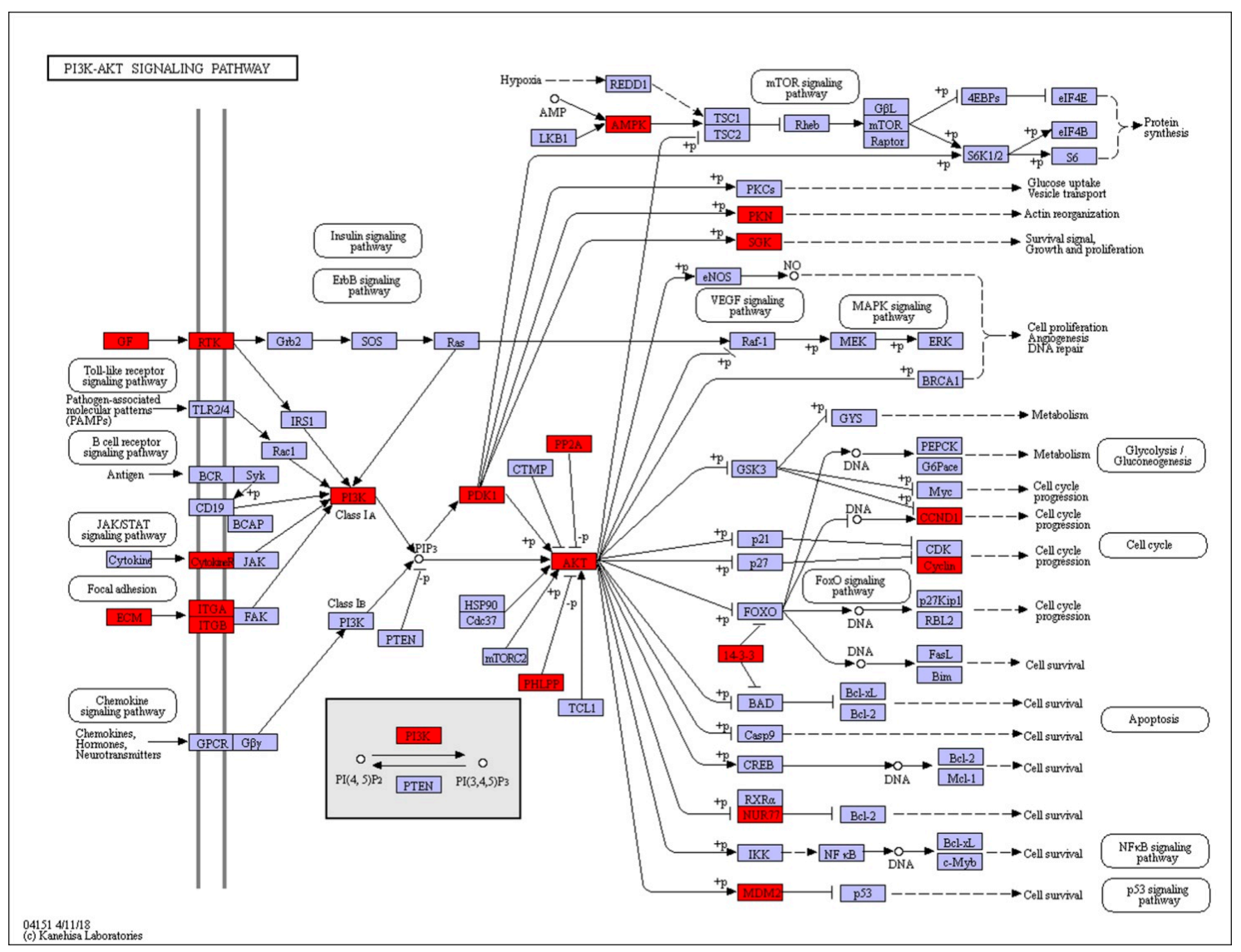

Figure 1. Model of activation of the PISK/AKT signalling pathway in mink uteri in activated versus diapause states. Differentially expressed genes are shown in red color. Genes in blue boxes were present in the mink transcriptome but not differentially expressed. 


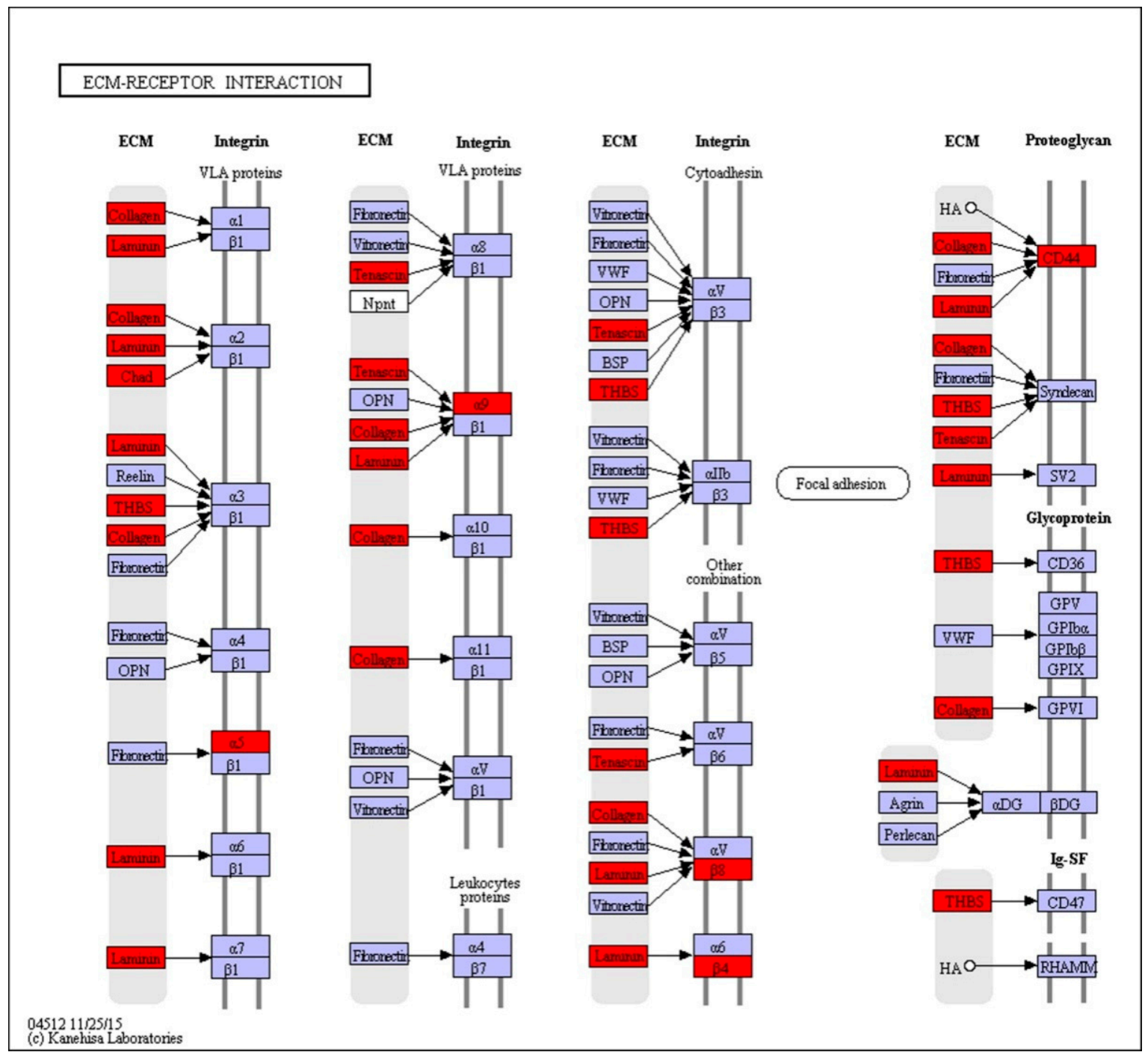

Figure 2. Model of activation of the extracellular matrix (ECM)-Receptor interaction pathway in the mink uterus in activated versus diapause states. Differentially expressed genes are shown in red color. Genes in blue boxes were present in the mink transcriptome but not differentially expressed.

\subsection{PPI Network Analysis}

Protein-protein interactions (PPIs) analysis can reveal the protein function of DEGs at the molecular level. In the present study, we used the STRING database to construct a gene network (Results in Supplementary materials). This network consisted of 354 nodes connected via 697 edges. The highly connected nodes, also known as hub genes, represent important genes in the network. We identified 6 hub nodes with a high connectivity degree $>20$ (Figure 4). The genes were AKT (41), EGF (36), P1K3C (25), IGF1 (24), CCND1 (22) and VEGFA (21). The data suggest that they play important roles in embryo activation in mink. 
Table 4. Most enriched pathways in the activated uterus vs. the diapause uterus at $p<0.01$.

\begin{tabular}{|c|c|c|}
\hline KEGG Pathway & $p$ Value & Genes \\
\hline ECM-receptor interaction & $1.61 \times 10^{-11}$ & 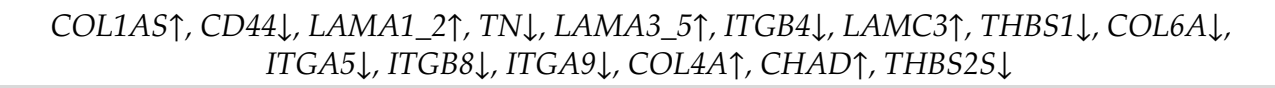 \\
\hline Focal adhesion & $7.53 \times 10^{-08}$ & 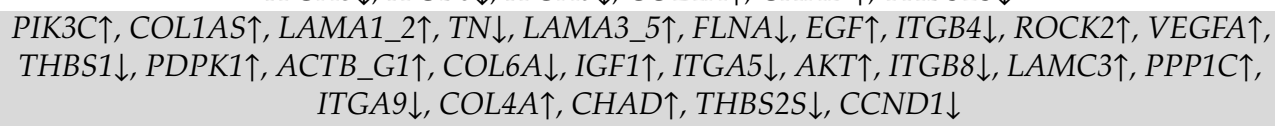 \\
\hline PI3K-Akt signaling pathway & $4.94 \times 10^{-7}$ & 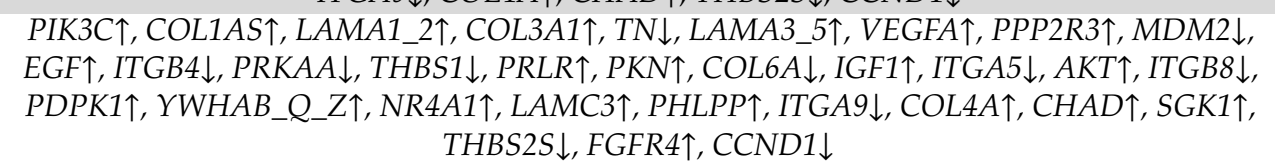 \\
\hline Cytokine-cytokine receptor interaction & $2.37 \times 10^{-2}$ & $\begin{array}{c}V E G F A \uparrow, T N F S F 12 \downarrow, I L 13 R A 1 \downarrow, C X C L 14 \downarrow, C S F 2 R B \uparrow, P R L R \uparrow, I L 1 A \uparrow, E G F \uparrow, T N F S F 18 \uparrow, L I F R \downarrow, \\
L T B R \downarrow, B M P R 1 B \uparrow\end{array}$ \\
\hline Protein digestion and absorption & $7.65 \times 10^{-6}$ & COL1AS $\uparrow, A C E 2 \uparrow, X P N P E P 2 \uparrow, C O L 6 A \downarrow, S L C 7 A 9 \downarrow, C O L 4 A \uparrow, S L C 15 A 1 \uparrow, A C E H \uparrow$ \\
\hline $\begin{array}{l}\text { AGE-RAGE signaling pathway in diabetic } \\
\text { complications }\end{array}$ & $6.35 \times 10^{-5}$ & PIK3C $\uparrow, C O L 1 A S \uparrow, P L C B \uparrow, V E G F A \uparrow, P L C D \uparrow, I L 1 A \uparrow, S T A T 5 A \downarrow, A K T \uparrow, C O L 4 A \uparrow, C C N D 1 \downarrow$ \\
\hline Cell adhesion molecules (CAMs) & $1.69 \times 10^{-3}$ & $\begin{aligned} M H C 2 \downarrow, C L D N \uparrow, I T G B 8 \downarrow, A L C A M \uparrow, & C D H 4 \uparrow, N C A M \uparrow, P T P R F \uparrow, S I G L E C 1 \downarrow, I T G A M \downarrow, I T G A 9 \downarrow, \\
& P T P R C \uparrow, N R C A M \uparrow\end{aligned}$ \\
\hline Glycine, serine and threonine metabolism & $3.54 \times 10^{-3}$ & GATM $\uparrow, \operatorname{ser} B \uparrow, S A R D H \uparrow, C T H \uparrow, g c v T \uparrow, D A O \uparrow, D L D \uparrow$ \\
\hline Thyroid hormone synthesis & $6.34 \times 10^{-3}$ & $P L C B \uparrow, G P X 8 \uparrow, T T F 2 \uparrow, S L C 26 A 4 \uparrow, L R P 2 \uparrow, A D C Y 7 \downarrow, P A X 8 \uparrow$ \\
\hline Platelet activation & $0.92 \times 10^{-2}$ & $R O C K 2 \uparrow, C O L 1 A S \uparrow, A K T \uparrow, P I K 3 C \uparrow, P L C B \uparrow, P P P 1 C \uparrow, A C T B \_G 1 \uparrow, A D C Y 7 \downarrow$ \\
\hline Prolactin signaling pathway & $0.50 \times 10^{-2}$ & ELF5 $\uparrow, P I K 3 C \uparrow, A K T \uparrow, C Y P 17 A \uparrow, P R L R \uparrow, S T A T 5 A \downarrow, C C N D 1 \downarrow$ \\
\hline
\end{tabular}




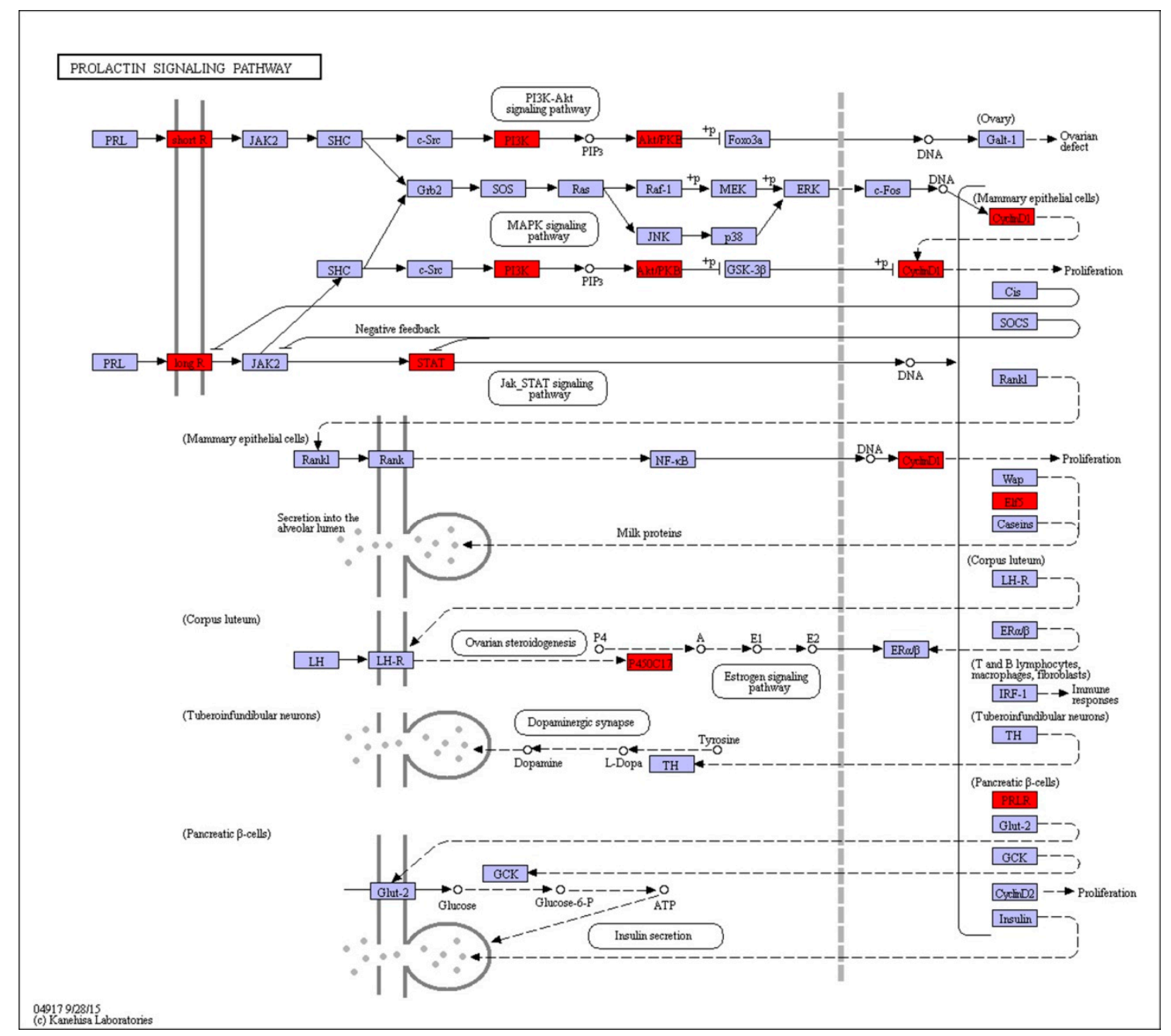

Figure 3. Model of activation of the prolactin signalling pathway in the mink uterus in activated versus diapause states. Differentially expressed genes are shown in red color. Genes in blue boxes were present in the mink transcriptome but not differentially expressed.

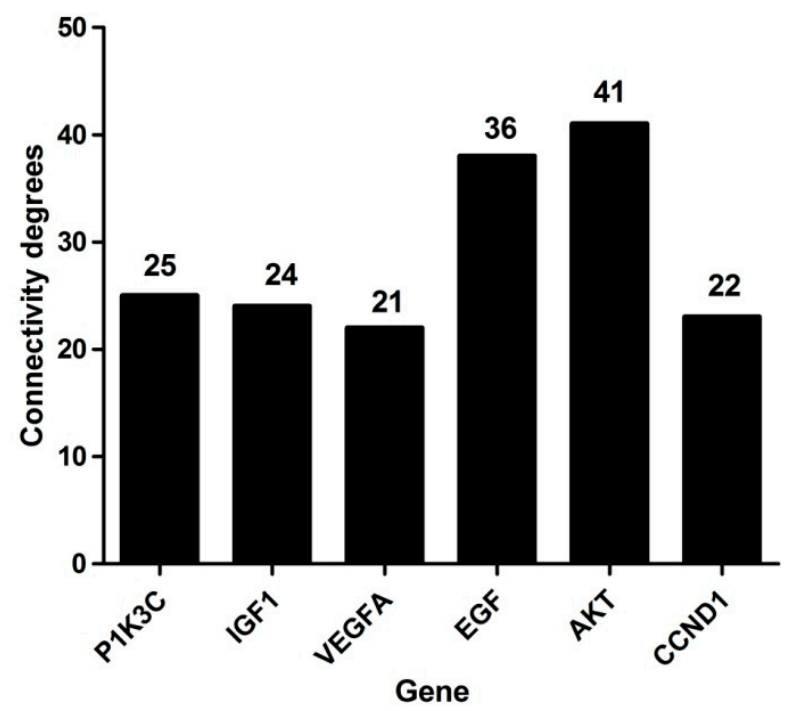

Figure 4. Connectivity degrees of the Protein-protein interactions (PPI) network. 


\subsection{Candidate Gene Selection and Validation of Expression Levels}

We used qPCR to validate 21 DEGs from the RNA-Seq analysis that have also been reported to be relevant to the physiology of implantation. Validation experiments were performed on RNA samples from biological replicates independent of the animals used for RNAseq analysis. As shown in Figure 5, the expression levels of EGF, HBEGF, ER, IGF1, LIF, FKBP4, ODC, ASMT, PDE11, MCM2, PIK3C2, SLC4A8, CD1,VEGFA, c-myc, PRLR and LAMA3 were elevated in the activated relative to the diapause uterus. The largest differences were 22-, 17- and 14-fold increases of the LIF, FKBP4, VEGFA transcripts, respectively. In contrast, the abundance of the EGFR, PMP22, GALNT and the progesterone receptor was reduced in the activated uterus. Two candidate genes, LIF and ESR1, did not show a significant difference in RNA-Seq result but differences were detected by qPCR.

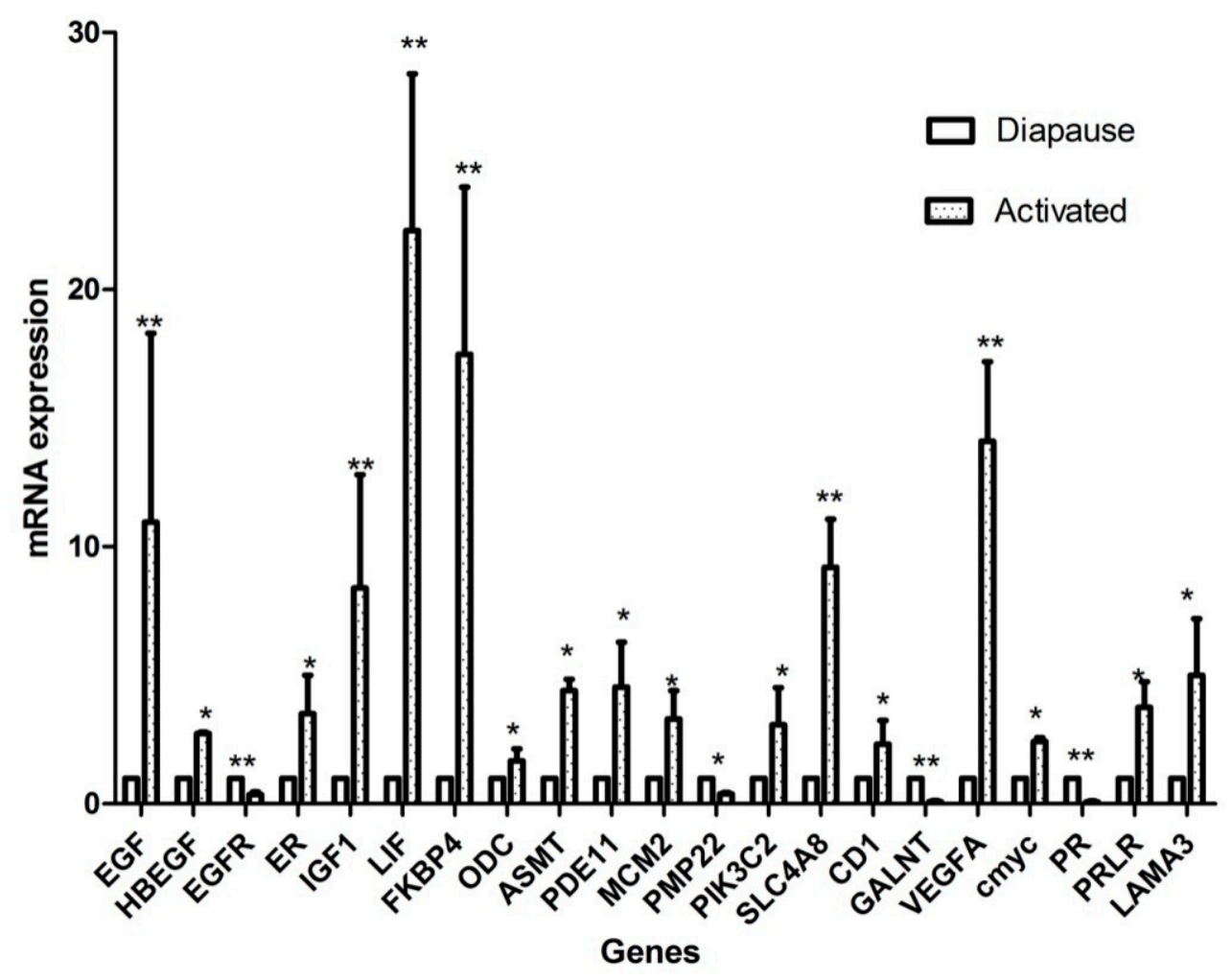

Figure 5. QRT-PCR validation of RNA-Seq data in mink uterus during embryo diapauses and activation: activated/diapause expression ratios. GAPDH was used as the internal control for mRNA analysis. The data shown are from three biological replicates. ${ }^{*} p<0.05,{ }^{* *} p<0.01$.

\subsection{Prolactin Activates Diapauses Embryo by PI3K Signaling Pathway}

To explore the role of PI3K/AKT pathway in the escape of embryo diapauses in mink, we cultured mink embryos with or without pathway inhibitor LY294002 (10 $\mu \mathrm{M}, 100 \mu \mathrm{M})$, Adding inhibitor into the embryo culture medium over five days significantly decreased the percentage of embryo survival and the diameter of surviving blastocysts, compared to those in the control group without inhibitor supplementation $(p<0.05$, Figure 6$)$. 


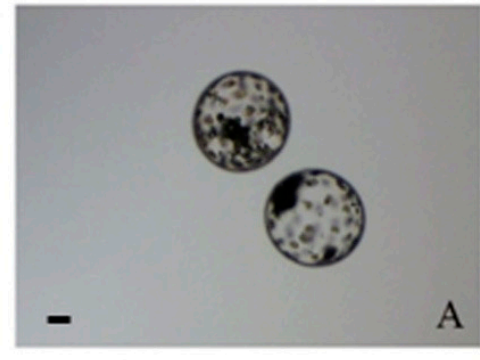

D

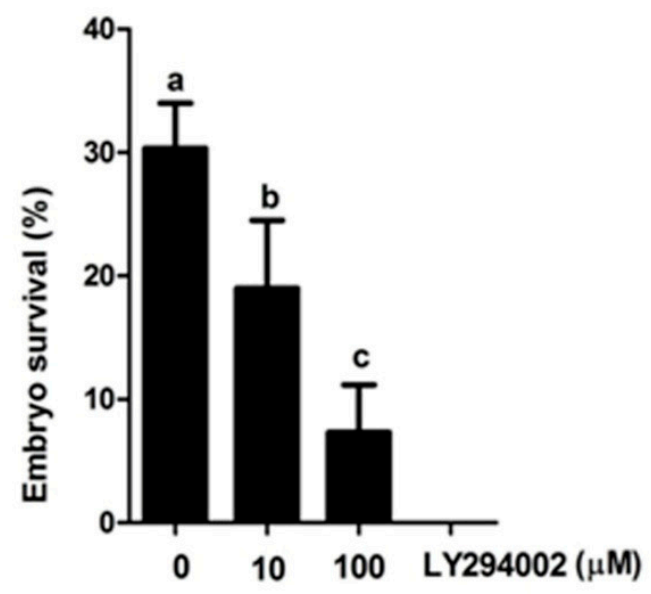

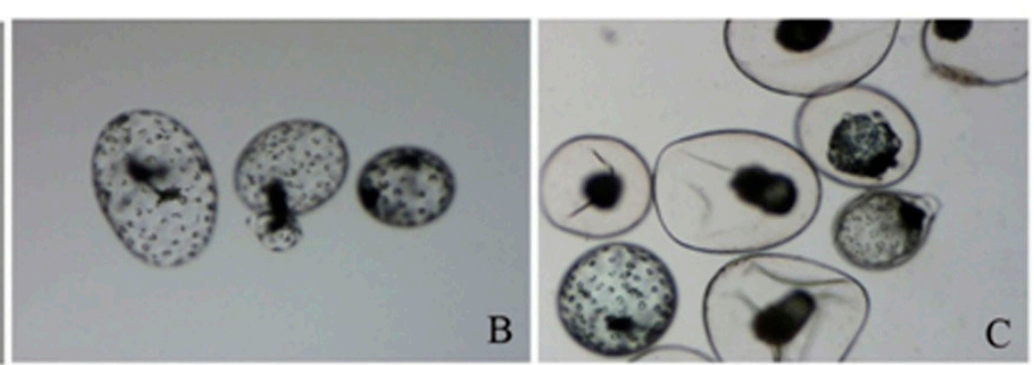

E

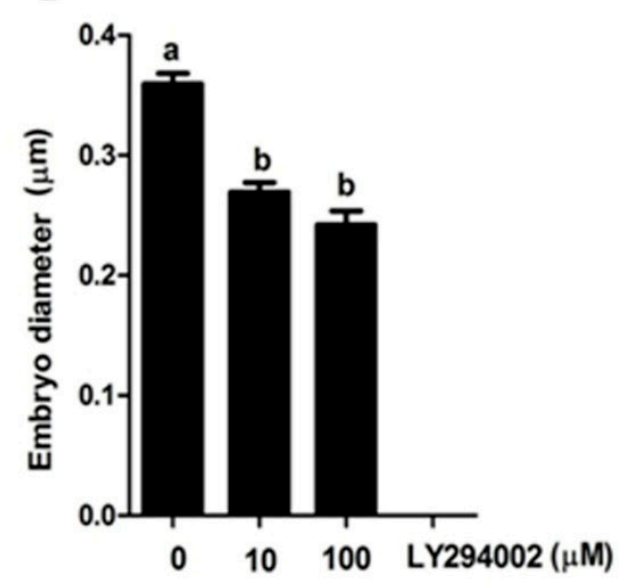

Figure 6. Mink embryos recovered in obligate diapause and cultured with different concentrations of the PI3K/AKT inhibitor (LY294002). The morphology of embryos was evaluated under a stereomicroscope. ( $\times$ 200) (A) Diapause embryos, (B) Expanded embryos indicative of reactivation, (C) Dead embryos, (D) Embryo survival after five days culture, (E) The mean diameter of the blastocysts after five days culture. Significant at $p<0.05$. Data are mean \pm SEM. Different small letters above columns indicate significant differences by Student's $t$-test.

\section{Discussion}

The mink is one of a large number of carnivores in which arrested development at the blastocyst stage occurs for a varying period of time [11]. In this species, the minimum duration of diapause is approximately six days and the average duration about 20 days. It is believed that the embryo is vulnerable during this period, and embryo loss during diapause contributes to gestational failure. Embryo transfer experiments have confirmed that embryo diapause is controlled by the uterine environment, and that developmental arrest is due to a lack of specific factors necessary for continued embryo development [3]. Establishing the crosstalk between the blastocyst in diapause and the uterus involves a number of complex signalling networks. In this study, we present the first application of RNA-Seq to characterize the uterine transcriptome during embryo diapause and activation in mink. More than 50 million clean reads were identified, and 170,984 unigenes were obtained from the clean reads using optimized parameters. A total of 1684 DEGs were generated for activated compared to uteri in diapause. Among these DEGs, we selected 21 to validate the accuracy of RNA-Seq by qRT-PCR, and found that the expression trend of these genes measured by qRT-PCR was consistent with RNA-Seq, suggesting that our data were of high quality.

Termination of embryonic diapause in this species is induced by prolactin from the pituitary gland, followed by ovarian luteal cell activation and secretion of progesterone, subsequently acting on the endometrium [12]. Prolactin receptor (PRLR) has been found in the uterus of mink. In our RNA-Seq results, the $P R L R$ was significantly increased (about 16-fold) in the activated compared to the diapause uterus. A recent report demonstrated that prolactin induces expression of factors essential for the termination of diapause in the mink [2]. PRLR deficiency resulting in implantation failure has been reported in mice [13]. The study showed that ovarian PRLR is required at implantation, while uterine 
PRLR may be essential for supporting late gestation. Previous studies have reported that prolactin, acting through its cognate receptor, exerts its role via the Jak2-Stat signaling pathway $[14,15]$. Other pathways, for example, tyrosine phosphorylation of phosphatidylinositol (PI)-3' kinase (P13K) are also involved in signal transduction by this receptor [16]. Our global transcriptome analysis indicates both of these intracellular signalling cascades are upregulated in the activated uterus, compared to the diapause counterpart. The existence of two PRL-dependent signalling cascades is initiated by the c-Src-mediated activation of Fak/Erk $1 / 2$ and P13K pathways that control the expression of c-Myc and cyclin D1 and, consequently, cell proliferation [17]. The P13K-Akt pathway is a well-known mediator of cell growth, proliferation, migration and angiogenesis [18-21]. During embryo implantation, the P13K-Akt pathway is involved in trophoblast invasion, immune surveillance and apoptosis [22-24]. In the present study, the signalling pathway was the most enriched KEGG pathway, in that 24 DEGs were upregulated and 11 DEGs were down-regulated in the activated uterus compared to the diapause uterus. Adding an inhibitor of this pathway during in vitro culture of embryos inhibited their development. Further investigation of downstream targets of these pathways is required to determine the uterine genes that regulate the reactivation of the mink embryo from diapause.

The up-regulated DEGs with the highest expression levels associated with activation were Ankyrin repeat and SAM domain-containing protein (ANKSIA). Ankyrin repeat proteins are found with diverse functions, which can be attributed to the presence of catalytic domains in various ankyrin repeat-containing proteins, for example, SH3, SAM and PDZ domains in addition to seven ankyrin repeats. These proteins are among the most frequently observed amino acid motifs in protein databases, and have received a great deal of attention recently. Defects in ankyrin repeat proteins has been found in a number of human diseases [25]. Our qRT-PCR validation indicated that the abundance of this transcript was significantly higher in the activated uterus compared to the diapause phase, however, little is known concerning the relationship between ANKSIA and embryo activation in mink. Therefore, we propose that ANKSIA may be positively involved in development of the receptive endometrium from the static state in mink.

Laminin alpha 3 (LAMA3) is a member of a secreted family of heterotrimeric molecules essential for basement membrane formation, cell migration and mechano-signal transduction. LAMA3 has been identified in the uterus of several species during implantation, and decreased expression may be associated with reduced uterine receptivity and infertility [26-28]. In the pig, RNA-Seq analysis in endometrial tissues during early pregnancy showed that $L A M A 3$ expression is upregulated during embryo implantation [26] and the present study demonstrated, for the first time, higher expression of $L A M A 3$ in the activated uterus of mink. These findings suggest that uterine LAMA3 expression is regulated in a stage-specific manner during early pregnancy, and that $L A M A 3$ may have a critical role in regulating embryo activation.

The DNA replication licensing factor MCM2 (Minichromosome maintenance protein 2), which is essential for eukaryotic DNA replication, is dynamically expressed in both proliferative and differentiated stromal cells in the mouse peri-implantation uterus and experimental reduction of MCM2 compromises stromal cell differentiation [29]. Studies using both in vivo and in vitro approaches demonstrated that the MCM2 protein is regulated by estrogen induced KLF4 (Kruppel-like family) expression, as progesterone levels increase, KLF15 is induced, and the abundance of MCM2 declines in uterine stromal cells [30]. Ovarian progesterone secretion increases at reactivation and levels of both progesterone and estradiol being high around implantation [31,32]. However, expression of neither progesterone nor estrogen receptors displayed increases in reactivated embryo and uterus in mink [2]. In the mink, prolactin is the main regulator of embryo implantation and the prolactin receptor expressed increases around the time of implantation [33-35]. Progesterone and/or estrogen does not induce implantation in mink, although they are sufficient to induce reactivation from diapause in the mouse and a number of other species [2]. This study showed that the progesterone receptor expression declined, while MCM2 expression increased during embryo activation in mink uterus, suggested a different mechanism with other mammals. 
Extracellular matrix (ECM)-receptor interaction and focal adhesion were the most predominant altered pathways in activated compared with diapause uteri. Previous studies have reported that a variety of $E C M$ proteins were present on the surface of uterine stromal cells [28,29], and these cell surface glycoproteins function in epithelial-embryonic interactions. The levels of a number of ECM molecules have been shown to peak during the "window of implantation" in mice [36]. In mink, we found 19 DEGs enriched into the pathway of ECM-receptor interaction, and 28 DEGs enriched into the focal adhesion pathway $(p<0.05)$. Although there has been extensive study of ECM in the uterus, the pathway of focal adhesion and interaction with ECM during embryo activation in the mink uterus is not well understood.

We also investigated the immune response between the diapause and activated uterus based on the importance of immunity in early maternal, fetal interactions. Several genes were identified, which may be involved in this process. Interleukin-1 (IL1A), which triggers cell activation via the functional signaling IL1R1. IL1 was shown to increase tumor invasiveness and metastasis by enhancing the expression of adhesion molecules on endothelial [37]. IL1 also stimulates the proliferation of endothelial cells and production of cytokines $[38,39]$. Besides its major immunological effects, IL1 regulates cell growth and angiogenesis by activating the VEGF-KDR pathway [38,40]. Early studies indicated an essential role of IL1 in implantation, as repeated injections of IL1 receptor antagonist into pregnant mice prior to implantation caused implantation failure [41]. In cattle, IL1A stimulates PGF2 $\alpha$ synthesis and secretion by endometrium in vitro and in vivo [42,43]. PGs are necessary for increased vascular permeability at the site of implantation [44] and are implicated in decidualization of rodent and human stromal cells $[45,46]$. In mink, expression of PTGS2, which is the regulated enzyme in PG synthesis, has been reported to be a transient event that occurs at the time of trophoblast attachment and invasion [5]. In addition, the genes with greater abundance in the activated compared with diapauses uterus, such as PRIMA1 (proline rich membrane anchor 1), GDF7 (growth differentiation factor 7), AGPAT9 (glycerol-3-phosphate acyltransferase 3), ATRNL1 (attractin-like 1), TNFSF18 (necrosis factor), COL1A1 (collagen type I), PHLPP1 (PH domain and leucine rich repeat protein phosphatase 1) and $S L C 9 A 8$ (cation proton antiporter 8) are associated with the immune response. Further studies are required to elucidate their potential roles.

In the innate immune pathways such as cytokine-cytokine receptor interaction, cytokines modulate the endometrial receptivity by regulating the expression of various adhesion molecules [47]. In mammals, deregulated expression of cytokines and their signaling leads to an absolute or partial failure of implantation and abnormal placental formation [48]. The CSF family (colony stimulating factor) of ligands and their receptors are increasingly recognized to play important roles in promoting proliferation of trophoblast cells, and have recently been used as therapeutic targets for recurrent implantation failure and pregnancy loss. Activin-like kinase 6 (ALK6, BMPR1B), is known to mediate BMP signalling. BMPR1B has been demonstrated to play an essential role in regulation of endometrial function and female fertility in mice and humans [49]. Tumor necrosis factor ligand superfamily member 18 (TNFSF18) are major proinflammatory cytokines that are known to induce structural and functional changes in endothelial cells. Adhesion between trophoblasts and endothelial cells can be increased by TNF [50]. All these cytokines are overexpressed in the activated relative to the diapause uterus. The genes with greater abundance in the activated uterus, such as VEGFA, PRLR and EGF, were also clustered into the pathways of cytokine-cytokine receptor interactions.

Using the STRING database, we obtained a network consisted of 354 nodes and 697 edges. In this network, we identified 6 hub genes. The hub genes were VEGFA (vascular endothelial growth factor A), EGF (epidermal growth factor), AKT (serine/threonine-protein kinase), PIK3C (phosphatidylinositol-4,5-bisphosphate 3-kinase, PI3K), IGF1 (insulin-like growth factor 1) and CCND1 (cyclin D1). VEGF is best known for its potent endothelial cell specific mitogenic activity, and plays a role in increasing vascular permeability [51]. Investigation of VEGF has shown that it is expressed during the peri-implantation period in mink [52], and the abundance of mRNA of VEGF isoforms was highest during embryo activation and at implantation, which is consistent with our RNA-Seq and 
Q-PCR result. EGF has been demonstrated to be a molecular marker in endometrial receptivity [53]. Its function may be to protect endometrial integrity, as EGF was decreased in human endometrium in women with luteal phase defects and pregnancy loss [54,55]. IGF1, which promoted the proliferation of endometrial cells, was expressed in all components of the mouse uterus, and its synthesis was regulated by estrogen acting through its nuclear receptor [56]. IGF1 knockout mice lack a uterine proliferative response to estrogen, specifically, lack G2/M progression of the epithelial cells [57]. It is worth mentioning that the hub genes PI3K/AKT were significantly upregulated in the activated uterus compared to the diapause phase consistent with the known role of prolactin in induction of implantation in this species. This is in agreement with our description in the KEGG analysis. PI3K proteins are key regulators involved in a wide variety of cellular processes, including endothelial proliferation, migration, differentiation and survival $[58,59]$. Exposure of the uterine lumen to an $A K T$ inhibitor prior to embryo transfer induced early pregnancy defects, ranging from implantation failure to aberrant spacing of implantation sites [60]. PI3K knockout mice exhibited impaired migration of endothelial cells and subsequent loss of angiogenic activity [61].

\section{Materials and Methods}

\subsection{Animals and Sample Collection}

All animal procedures were conducted under guidelines of the Experimental Animal Use and Care Committee of the Institute of Special Animal and Plant Sciences, Chinese Academy of Agricultural Sciences and pre-approved prior to implementation (permit no. ISAPSWAPS2016000302. 2016/5/20). Female mink were mated to two fertile males, at 7-9 day intervals, according to the usual commercial farming procedures. Successful matings were confirmed by the presence of motile spermatozoa in vaginal smears.

Mink were subjected to general anesthesia prior to collection of samples. Uterine horns from females during diapause were collected prior to March 21 and 7-9 days after the final mating. Termination of embryo diapause was performed by injecting $1 \mathrm{mg} \mathrm{kg}^{-1}$ day $^{-1}$ ovine prolactin (Sigma-Aldrich, L6520, Saint Louls, USA) each day beginning on March 21 and for the following five days [12]. The first day of prolactin injection was designated day 1 after blastocyst reactivation. Unimplanted blastocysts were flushed from the uterus using TC-199 medium (Gibco, 11150-067, Carsbad, USA) supplemented with $10 \%$ fetal bovine serum (Gibco, 16000-044,Carsbad, CA, USA). Blastocyst diameters were measured to confirm that embryos were activated, as described previously [12]. For transcriptome analysis, uterine horns were collected during diapause and on the sixth day after prolactin-induced reactivation, and stored in liquid nitrogen until subsequent transcriptome analysis.

\subsection{RNA Sequencing}

Total RNA extracted from uterus samples using TRIzol ${ }^{\circledR}$ reagent (Invitrogen, $n=3$ for each diapause and activated group). RNA integrity was evaluated by Agilent Bioanalyzer 2100 system (Agilent Technologies, Santa Clara, CA, USA), RNA degradation and contamination was detected on $1 \%$ agarose gels. RNA concentration was determined using the Qubit ${ }^{\circledR}$ 2.0 Fluorometer (Life Technologies, South San Francisco, CA, USA), and purity was determined by NanoPhotometer ${ }^{\circledR}$ spectrophotometer (IMPLEN, California, CA, USA). A total amount of $1.5 \mu \mathrm{g}$ RNA per sample was used as input material for the RNA sample preparations. Sequencing libraries were constructed using the NEBNext ${ }^{\circledR}$ Ultra $^{\text {TM }}$ RNA Library Prep Kit for Illumina ${ }^{\circledR}$ (NEB, Boston, MA, USA) following the manufacturer's recommendations, and index codes were added to attribute sequences to each sample. The clustering of the index-coded samples was performed on a cBot Cluster Generation System using TruSeq PE Cluster Kit v3-cBot-HS (Illumia) according to the manufacturer's instructions. After cluster generation, the library preparations were sequenced on an Illumina Hiseq platform and $150 \mathrm{bp}$ paired-end reads were generated. Raw data (raw reads) of fastq format were first processed through in-house perl scripts. In this step, clean data (clean reads) were obtained by removing reads containing 
adapter, reads containing poly-N and low quality reads from raw data. All the downstream analyses were based on clean data of high quality. Transcriptome assembly was accomplished based on the left.fq and right.fq using Trinity [62] with min_kmer_cov set to 2 by default and all other parameters set default. Gene function was annotated based on the following databases: $\mathrm{Nr}$ (NCBI non-redundant protein sequences), Nt (NCBI non-redundant nucleotide sequences), Pfam (Protein family), KOG/COG (Clusters of Orthologous Groups of proteins), Swiss-Prot (A manually annotated and reviewed protein sequence database), KO (KEGG Ortholog database) and GO (Gene Ontology). Differential expression analysis of two groups was performed using the DESeq R package [63]. The Benjamini and Hochberg approaches were used to adjust $p$ values and control the false discovery rate. $p<0.05$ in DESeq were assigned as differentially expressed.

\subsection{Enrichment Analysis of DEGs}

Gene Ontology (GO) enrichment analysis of the DEGs was performed by GOseq R packages based Wallenius non-central hyper-geometric distribution [64]. KOBAS [65] software was used to test the statistical enrichment of DEGs in KEGG pathway. The threshold for the DEGs was set as $p<0.05$.

\subsection{Validation of DEGs}

Total RNA was extracted from uteri in diapause and activation phases with Trizol (Invitrogen, 15596018, Carlsbad, USA) according to the manufacturer's specifications. The yield of RNA was determined using a NanoDrop 2000 spectrophotometer (Thermo Scientific, Wilmington, NC, USA), and the integrity was evaluated using agarose gel electrophoresis stained with ethidium bromide. Reverse transcribed was performed using PrimeScript ${ }^{\mathrm{TM}}$ RT reagent kit (TAKARA, RR036Q, Kyoto, Japan) with $10 \mu \mathrm{L}$ reaction system, including $2 \mu \mathrm{L}$ 5xPrimeScript Buffer, $0.5 \mu \mathrm{L}$ PrimeScript RT Enzyme Mix 1, $0.5 \mu \mathrm{L}$ Oligo dT Primer $(50 \mu \mathrm{M}), 0.5 \mu \mathrm{L}$ Random 6 mers $(100 \mu \mathrm{M}), 2 \mu \mathrm{L}$ total RNA and $4.5 \mu \mathrm{L}$ RNase Free $\mathrm{dH}_{2} \mathrm{O}$ and stored in $-20^{\circ} \mathrm{C}$. Real-time PCR was determined using a LightCycler ${ }^{\circledR} 480$ IIReal-time PCR Instrument (Roche, Basilea, Switzerland) with $20 \mu \mathrm{L}$ PCR reaction mixture that included $10 \mu \mathrm{L} 2 \times \mathrm{SG}$ Fast qPCR Master Mix (Sangon Biotech B639271, Shanghai, China), $0.4 \mu \mathrm{L}$ of forward primer, $0.4 \mu \mathrm{L}$ of reverse primer, $2 \mu \mathrm{L}$ DNF buffer, $1 \mu \mathrm{L}$ of cDNA and $6.2 \mu \mathrm{L}$ PCR-grade water. Reaction condition was $95^{\circ} \mathrm{C}$ for $3 \mathrm{~min}, 95^{\circ} \mathrm{C}$ for $3 \mathrm{~s}$ for 40 cycles and $60^{\circ} \mathrm{C}$ for $30 \mathrm{~s}$. Each sample was run in triplicate for analysis. In the end of the PCR cycles, melting curve analysis was performed to validate the specific generation of the expected PCR product. The expression levels of mRNAs were normalized to GAPDH and were calculated using the $2^{-\Delta \Delta C t}$ method [66].

\subsection{PPI (Protein Protein Interaction) Network Construction}

The sequences of DEGs were determined by BLASTX using the genome of a related species. The protein-protein interaction of which exists in the STRING database (http://string-db.org/) was employed to get the predicted PPI of these DEGs. Then, the PPI of these DEGs were visualized in Cytoscape [67]. In the PPI network, nodes stand for proteins, and edges represent interactions between 2 proteins.

\subsection{Embryo Culture}

Blastocysts in diapause were collected by uterine flushing and washed three times in TCM199 medium supplementation with 10\% (v/v) fetal bovine serum (Invitrogen). Embryos were cultured in groups of 10-12 in $400 \mu 1$ M16 Medium (Sigma-Aldrich, M7292,Saint Louls, MO, USA) supplementation with $10 \mu \mathrm{g} / \mathrm{mL}$ prolactin at $37^{\circ} \mathrm{C}$ under $5 \% \mathrm{CO}_{2}$ in humidified air, depending on the experiment, concentrations of 0,10 or $100 \mu \mathrm{M}$ solutions of LY294002 were prepared in dimethyl sulfoxide (DMSO) and diluted in culture medium to the desired final concentration. DMSO was added to control culture, and all examined culture droplets contained 0.1\% DMSO. Medium was changed every two days, and embryo diameters were measured by ocular micrometer after 5 days. Determination of death 
of embryos was based on observation of shrinkage of the blastocyst, blastocele size reduction or no blastocele observed. Experiments were repeated at least three times.

\subsection{Statistical Analyses}

For GO and pathway enrichment analysis, $p<0.05$ was considered to indicate a statistically significant difference. $p$-values were adjusted using the false discovery rate (FDR) method for multiple hypothesis testing. FDR $<0.05$ was established as the threshold value. For embryo culture experiment, data were analyzed by ANOVA, using statistics package for social science (SPSS) software. Percentage data were arc-sine transformed, a Duncan multiple comparison test was used to locate differences. For the qPCR analysis, a two-tail unequal variance student $t$ test was used to compare the messenger RNA (mRNA) expression levels between diapause and reactivation uterus.Data were expressed as mean \pm S.E.M and $p<0.05$ was considered significant.

\section{Conclusions}

The comparison of the transcriptome between uteri during diapause and following reactivation of the embryo presented here indicates that multiple regulatory pathways are activated during the escape of the from diapause. Hormones provide a suitable physiologic milieu for embryo implantation. Acquired diseases or alteration in maternal physiology during embryo implantation can affect endometrial function and fetal development. The prolactin signaling pathway and its downstream PI3K/AKT pathway are the most enriched pathways in activated compared to diapause uterus, blocking the pathway with inhibitor decreased embryo development, our previous study have demonstrated the importance of these pathways on embryo invasive in mink [68]. Further investigation is needed to amplify and validate the current study with details of the localization and function of important genes and proteins, which may allow us to better understand what is required to drive embryo development and help develop new strategies for promoting successful pregnancy in mink.

Supplementary Materials: Supplementary materials can be found at http://www.mdpi.com/1422-0067/20/9/2099/s1.

Author Contributions: X.C. and B.D.M. conceived and designed the experiments. J.Z. and Y.L. performed the experiments. H.B. and H.W. participated in sample collection, Y.Z. and G.W. analyzed the data. X.X. contributed reagents and materials. X.C. and B.D.M. wrote the manuscript.

Funding: This study was supported by National Natural science foundation of China (31501958); Natural science foundation of Jilin province (20180101258JC). Science and Technology Innovation Program of the Chinese Academy of Agricultural Sciences and a grant from the Natural Sciences and Engineering Research Council of Canada to Bruce D. Murphy.

Conflicts of Interest: The authors declare no conflict of interest.

\section{References}

1. Enders, R.K. Reproduction in the mink (Mustela vison). Am. Philos. Soc. 1952, 96, 691-755.

2. Fenelon, J.C.; Banerjee, A.; Lefevre, P.; Gratian, F.; Murphy, B.D. Polyamine-Mediated Effects of Prolactin Dictate Emergence from Mink Obligate Embryonic Diapause. Biol. Reprod. 2016, 95, 6. [CrossRef] [PubMed]

3. Chang, M. Reciprocal insemination and egg transfer between ferrets and mink. Ecol. Genet. Physiol. 1968, 168, 49-59. [CrossRef]

4. Moreau, G.M.; Arslan, A.; Douglas, D.A.; Song, J.; Smith, L.C.; Murphy, B.D. Development of immortalized endometrial epithelial and stromal cell lines from the mink (Mustela vison) uterus and their effects on the survival in vitro of mink blastocysts in obligate diapause. Biol. Reprod. 1995, 53, 511-518. [CrossRef] [PubMed]

5. Song, J.H.; Houde, A.; Murphy, B.D. Cloning of leukemia inhibitory factor (LIF) and its expression in the uterus during embryonic diapause and implantation in the mink (Mustela vison). Mol. Reprod. Dev. 1998, 51, 13-21. [CrossRef] 
6. Desmarais, J.A.; Cao, M.; Bateman, A.; Murphy, B.D. Spatiotemporal expression pattern of progranulin in embryo implantation and placenta formation suggests a role in cell proliferation, remodeling, and angiogenesis. Reproduction 2008, 136, 247-257. [CrossRef] [PubMed]

7. Lefevre, P.L.; Palin, M.F.; Beaudry, D.; Dobias-Goff, M.; Desmarais, J.A.; Llerena, E.M.; Murphy, B.D. Uterine signaling at the emergence of the embryo from obligate diapause. Am. J. Physiol. Endocrinolog. Metab. 2011, 300, E800-E808. [CrossRef] [PubMed]

8. Zhang, L.; An, X.P.; Liu, X.R.; Fu, M.Z.; Han, P.; Peng, J.Y.; Hou, J.X.; Zhou, Z.Q.; Cao, B.Y.; Song, Y.X. Characterization of the Transcriptional Complexity of the Receptive and Pre-receptive Endometria of Dairy Goats. Sci. Rep. 2015, 5, 14244. [CrossRef] [PubMed]

9. Samborski, A.; Graf, A.; Krebs, S.; Kessler, B.; Reichenbach, M.; Reichenbach, H.D.; Ulbrich, S.E.; Bauersachs, S. Transcriptome changes in the porcine endometrium during the preattachment phase. Biol. Reprod. 2013, 89, 134. [CrossRef]

10. McRae, A.C. Observation on the Timing of Embryo Mortality in Ranch Mink (Mustela Vison); Canada Mink Breeders Association: Toronto, Canada, 1992; pp. 35-48.

11. Fenelon, J.C.; Shaw, G.; Frankenberg, S.R.; Murphy, B.D.; Renfree, M.B. Embryo arrest and reactivation: potential candidates controlling embryonic diapause in the tammar wallaby and mink. Biol. Reprod. 2017, 96, 877-894. [CrossRef]

12. Desmarais, J.A.; Bordignon, V.; Lopes, F.L.; Smith, L.C.; Murphy, B.D. The escape of the mink embryo from obligate diapause. Biol. Reprod. 2004, 70, 662-670. [CrossRef] [PubMed]

13. Reese, J.; Binart, N.; Brown, N.; Ma, W.G.; Paria, B.C.; Das, S.K.; Kelly, P.A.; Dey, S.K. Implantation and decidualization defects in prolactin receptor (PRLR)-deficient mice are mediated by ovarian but not uterine PRLR. Endocrinology 2000, 141, 1872-1881. [CrossRef]

14. Brockman, J.L.; Schroeder, M.D.; Schuler, L.A. PRL activates the cyclin D1 promoter via the Jak2/Stat pathway. Mol. Endocrinol. 2002, 16, 774-784. [CrossRef] [PubMed]

15. Jabbour, H.N.; Critchley, H.O.; Boddy, S.C. Expression of functional prolactin receptors in nonpregnant human endometrium: Janus kinase-2, signal transducer and activator of transcription-1 (STAT1), and STAT5 proteins are phosphorylated after stimulation with prolactin. J. Clin. Endocrinol. Metab. 1998, 83, 2545-2553. [CrossRef]

16. Berlanga, J.J.; Gualillo, O.; Buteau, H.; Applanat, M.; Kelly, P.A.; Edery, M. Prolactin activates tyrosyl phosphorylation of insulin receptor substrate 1 and phosphatidylinositol-3-OH kinase. J. Biol. Chem. 1997, 272, 2050-2052. [CrossRef] [PubMed]

17. Bachelot, A.; Binart, N. Reproductive role of prolactin. Reproduction 2007, 133, 361-369. [CrossRef]

18. Dai, J.; Peng, L.; Fan, K.; Wang, H.; Wei, R.; Ji, G.; Cai, J.; Lu, B.; Li, B.; Zhang, D.; et al. Osteopontin induces angiogenesis through activation of PI3K/AKT and ERK1/2 in endothelial cells. Oncogene 2009, 28, 3412-3422. [CrossRef]

19. Karar, J.; Maity, A. PI3K/AKT/mTOR Pathway in Angiogenesis. Front. Mol. Neurosci. 2011, 4, 51. [CrossRef] [PubMed]

20. Goncharova, E.A.; Ammit, A.J.; Irani, C.; Carroll, R.G.; Eszterhas, A.J.; Panettieri, R.A.; Krymskaya, V.P. PI3K is required for proliferation and migration of human pulmonary vascular smooth muscle cells. Am. J. Physiol. Lung Cell. Mol. Physiol. 2002, 283, L354-L363. [CrossRef]

21. Bakin, A.V.; Tomlinson, A.K.; Bhowmick, N.A.; Moses, H.L.; Arteaga, C.L. Phosphatidylinositol 3-kinase function is required for transforming growth factor beta-mediated epithelial to mesenchymal transition and cell migration. J. Biol. Chem. 2000, 275, 36803-36810. [CrossRef]

22. Zeng, X.; Mao, X.; Huang, Z.; Wang, F.; Wu, G.; Qiao, S. Arginine enhances embryo implantation in rats through $\mathrm{PI} 3 \mathrm{~K} / \mathrm{PKB} / \mathrm{mTOR} / \mathrm{NO}$ signaling pathway during early pregnancy. Reproduction 2013, 145, 1-7. [CrossRef]

23. Banerjee, P.; Sapru, K.; Strakova, Z.; Fazleabas, A.T. Chorionic gonadotropin regulates prostaglandin E synthase via a phosphatidylinositol 3-kinase-extracellular regulatory kinase pathway in a human endometrial epithelial cell line: implications for endometrial responses for embryo implantation. Endocrinology 2009, 150, 4326-4337. [CrossRef]

24. Gentilini, D.; Busacca, M.; Di Francesco, S.; Vignali, M.; Vigano, P.; Di Blasio, A.M. PI3K/Akt and ERK1/2 signalling pathways are involved in endometrial cell migration induced by 17 beta-estradiol and growth factors. Mol. Hum. Reprod. 2007, 13, 317-322. [CrossRef] [PubMed] 
25. Mosavi, L.K.; Cammett, T.J.; Desrosiers, D.C.; Peng, Z.Y. The ankyrin repeat as molecular architecture for protein recognition. Protein Sci. 2004, 13, 1435-1448. [CrossRef] [PubMed]

26. Lin, H.; Wang, H.; Wang, Y.; Liu, C.; Wang, C.; Guo, J. Transcriptomic Analysis of the Porcine Endometrium during Embryo Implantation. Genes 2015, 6, 1330-1346. [CrossRef] [PubMed]

27. Zhao, Y.; Garcia, J.; Kolp, L.; Cheadle, C.; Rodriguez, A.; Vlahos, N.F. The impact of luteal phase support on gene expression of extracellular matrix protein and adhesion molecules in the human endometrium during the window of implantation following controlled ovarian stimulation with a GnRH antagonist protocol. Fertil. Steril. 2010, 94, 2264-2271. [CrossRef] [PubMed]

28. Kim, M.S.; Yu, J.H.; Lee, M.Y.; Kim, A.L.; Jo, M.H.; Kim, M.; Cho, S.R.; Kim, Y.H. Differential Expression of Extracellular Matrix and Adhesion Molecules in Fetal-Origin Amniotic Epithelial Cells of Preeclamptic Pregnancy. PLoS ONE 2016, 11, e0156038. [CrossRef]

29. Kong, S.; Han, X.; Cui, T.; Zhou, C.; Jiang, Y.; Zhang, H.; Wang, B.; Wang, H.; Zhang, S. MCM2 mediates progesterone-induced endometrial stromal cell proliferation and differentiation in mice. Endocrine 2016, 53, 595-606. [CrossRef]

30. Ray, S.; Pollard, J.W. KLF15 negatively regulates estrogen-induced epithelial cell proliferation by inhibition of DNA replication licensing. Proc. Natl. Acad. Sci. USA 2012, 109, E1334-E1343. [CrossRef]

31. Pilbeam, T.E.; Concannon, P.W.; Travis, H.F. The annual reproductive cycle of mink (Mustela vison). J. Anim. Sci. 1979, 48, 578-584. [CrossRef]

32. Rozhnov, V.V.; Naidenko, S.V.; Naidenko, S.V. Variation of the level of steroid hormones in the blood plasma of three Mustelide Species (Mammalia, Carnivora, Mustelidae) during the annual cycle. Dokl. Biol. Sci. 2007, 413, 121-124. [CrossRef]

33. Papke, R.L.; Concannon, P.W.; Travis, H.F.; Hansel, W. Control of luteal function and implantation in the mink by prolactin. J. Anim. Sci. 1980, 50, 1102-1107. [CrossRef] [PubMed]

34. Murphy, B.D.; Concannon, P.W.; Travis, H.F.; Hansel, W. Prolactin: the hypophyseal factor that terminates embryonic diapause in mink. Biol. Reprod. 1981, 25, 487-491. [CrossRef] [PubMed]

35. Murphy, B.D.; Mead, R.A.; McKibbin, P.E. Luteal contribution to the termination of preimplantation delay in mink. Biol. Reprod. 1983, 28, 497-503. [CrossRef] [PubMed]

36. Spiess, K.; Teodoro, W.R.; Zorn, T.M. Distribution of collagen types I, III, and V in pregnant mouse endometrium. Connect. Tissue Res. 2007, 48, 99-108. [CrossRef] [PubMed]

37. Vidal-Vanaclocha, F.; Alvarez, A.; Asumendi, A.; Urcelay, B.; Tonino, P.; Dinarello, C.A. Interleukin 1 (IL-1)-dependent melanoma hepatic metastasis in vivo; increased endothelial adherence by IL-1-induced mannose receptors and growth factor production in vitro. J. Natl. Cancer Inst. 1996, 88, 198-205. [CrossRef]

38. Apte, R.N.; Voronov, E. Is interleukin-1 a good or bad 'guy' in tumor immunobiology and immunotherapy? Immunological 2008, 222, 222-241. [CrossRef]

39. Meager, A. Cytokine regulation of cellular adhesion molecule expression in inflammation. Cytokine Growth Factor Rev. 1999, 10, 27-39. [CrossRef]

40. Sheth, K.V.; Roca, G.L.; al-Sedairy, S.T.; Parhar, R.S.; Hamilton, C.J.; al-Abdul Jabbar, F. Prediction of successful embryo implantation by measuring interleukin-1-alpha and immunosuppressive factor(s) in preimplantation embryo culture fluid. Fertil. Steril. 1991, 55, 952-957. [CrossRef]

41. Simon, C.; Valbuena, D.; Krussel, J.; Bernal, A.; Murphy, C.R.; Shaw, T.; Pellicer, A.; Polan, M.L. Interleukin-1 receptor antagonist prevents embryonic implantation by a direct effect on the endometrial epithelium. Fertil. Steril. 1998, 70, 896-906. [CrossRef]

42. Tanikawa, M.; Lee, H.Y.; Watanabe, K.; Majewska, M.; Skarzynski, D.J.; Park, S.B.; Lee, D.S.; Park, C.K.; Acosta, T.J.; Okuda, K. Regulation of prostaglandin biosynthesis by interleukin-1 in cultured bovine endometrial cells. J. Endocrinol. 2008, 199, 425-434. [CrossRef]

43. Majewska, M.; Woclawek-Potocka, I.; Bah, M.M.; Hapunik, J.; Piotrowska, K.K.; Tasaki, Y.; Acosta, T.J.; Okuda, K.; Skarzynski, D.J. Is interleukin-1 $\alpha$ a luteotrophic or luteolytic agent in cattle? Reproduction 2010, 139, 665-672. [CrossRef] [PubMed]

44. Kennedy, T.G. Timing of uterine sensitivity for the decidual cell reaction: role of prostaglandins. Biol. Reprod. 1980, 22, 519-525. [CrossRef]

45. Yee, G.M.; Kennedy, T.G. Prostaglandin E2, cAMP and cAMP-dependent protein kinase isozymes during decidualization of rat endometrial stromal cells in vitro. Prostaglandins 1993, 46, 117-138. [CrossRef] 
46. Han, S.W.; Lei, Z.M.; Rao, C.V. Up-regulation of cyclooxygenase-2 gene expression by chorionic gonadotropin during the differentiation of human endometrial stromal cells into decidua. Endocrinology 1996, 137, 1791-1797. [CrossRef] [PubMed]

47. Simon, C.; Martin, J.C.; Pellicer, A. Paracrine regulators of implantation. Best Pract. Res. Clin. Obstet. Gynaecol. 2000, 14, 815-826. [CrossRef] [PubMed]

48. Guzeloglu-Kayisli, O.; Kayisli, U.A.; Taylor, H.S. The role of growth factors and cytokines during implantation: endocrine and paracrine interactions. Semin. Reprod. Med. 2009, 27, 62-79. [CrossRef] [PubMed]

49. Clementi, C.; Tripurani, S.K.; Large, M.J.; Edson, M.A.; Creighton, C.J.; Hawkins, S.M.; Kovanci, E.; Kaartinen, V.; Lydon, J.P.; Pangas, S.A.; et al. Activin-like kinase 2 functions in peri-implantation uterine signaling in mice and humans. PLoS Genet. 2013, 9, e1003863. [CrossRef] [PubMed]

50. Todt, J.C.; Yang, Y.; Lei, J.; Lauria, M.R.; Sorokin, Y.; Cotton, D.B.; Yelian, F.D. Effects of tumor necrosis factor-alpha on human trophoblast cell adhesion and motility. Am. J. Reprod. Immunol. 1996, 36, 65-71. [CrossRef]

51. Keck, P.J.; Hauser, S.D.; Krivi, G.; Sanzo, K.; Warren, T.; Feder, J.; Connolly, D.T. Vascular permeability factor, an endothelial cell mitogen related to PDGF. Science 1989, 246, 1309-1312. [CrossRef] [PubMed]

52. Lopes, F.L.; Desmarais, J.; Gevry, N.Y.; Ledoux, S.; Murphy, B.D. Expression of vascular endothelial growth factor isoforms and receptors Flt- 1 and KDR during the peri-implantation period in the mink, Mustela vison. Biol. Reprod. 2003, 68, 1926-1933. [CrossRef] [PubMed]

53. Aghajanova, L.; Bjuresten, K.; Altmae, S.; Landgren, B.M.; Stavreus-Evers, A. HB-EGF but not amphiregulin or their receptors HER1 and HER4 is altered in endometrium of women with unexplained infertility. Reprod. Sci. 2008, 15, 484-492. [CrossRef] [PubMed]

54. Francis, J.; Rai, R.; Sebire, N.J.; El-Gaddal, S.; Fernandes, M.S.; Jindal, P.; Lokugamage, A.; Regan, L.; Brosens, J.J. Impaired expression of endometrial differentiation markers and complement regulatory proteins in patients with recurrent pregnancy loss associated with antiphospholipid syndrome. Mol. Hum. Reprod. 2006, 12, 435-442. [CrossRef] [PubMed]

55. Young, S.L.; Lessey, B.A.; Fritz, M.A.; Meyer, W.R.; Murray, M.J.; Speckman, P.L.; Nowicki, B.J. In vivo and in vitro evidence suggest that HB-EGF regulates endometrial expression of human decay-accelerating factor. J. Clin. Endocrinol. Metab. 2002, 87, 1368-1375. [CrossRef] [PubMed]

56. Ohtsuki, T.; Otsuki, M.; Murakami, Y.; Hirata, K.; Takeuchi, S.; Takahashi, S. Alternative leader-exon usage in mouse IGF-I mRNA variants: class 1 and class 2 IGF-I mRNAs. Zool. Sci. 2007, 24, 241-247. [CrossRef] [PubMed]

57. Diane, M.K.; Hewitt, S.C.; Ciana, P.; Raviscioni, M.; Lindzey, J.K.; Foley, J.; Maggi, A.; DiAugustine, R.P.; Korach, K.S. Requirement of estrogen receptor- $\alpha$ in insulin-like growth factor-1 (IGF-1)-induced uterine responses and in vivo evidence for IGF-1/estrogen receptor cross-talk. J. Biol. Chem. 2002, 277, 8531-8537.

58. Gerber, R.T.; Anwar, M.A.; Poston, L. Enhanced acetylcholine induced relaxation in small mesenteric arteries from pregnant rats: an important role for endothelium-derived hyperpolarizing factor (EDHF). Br. J. Pharmacol. 1998, 125, 455-460. [CrossRef]

59. Jiang, B.H.; Zheng, J.Z.; Aoki, M.; Vogt, P.K. Phosphatidylinositol 3-kinase signaling mediates angiogenesis and expression of vascular endothelial growth factor in endothelial cells. Proc. Natl. Acad. Sci. USA 2000, 97, 1749-1753. [CrossRef]

60. Salker, M.S.; Steel, J.H.; Hosseinzadeh, Z.; Nautiyal, J.; Webster, Z.; Singh, Y.; Brucker, S.; Lang, F.; Brosens, J.J. Activation of SGK1 in Endometrial Epithelial Cells in Response to PI3K/AKT Inhibition Impairs Embryo Implantation. Cell. Physiol. Biochem. 2016, 39, 2077-2087. [CrossRef]

61. Graupera, M.; Guillermet-Guibert, J.; Foukas, L.C.; Phng, L.K.; Cain, R.J.; Salpekar, A.; Pearce, W.; Meek, S.; Millan, J.; Cutillas, P.R.; et al. Angiogenesis selectively requires the p110alpha isoform of PI3K to control endothelial cell migration. Nature 2008, 453, 662-666. [CrossRef]

62. Grabherr, M.G.; Haas, B.J.; Yassour, M.; Levin, J.Z.; Thompson, D.A.; Amit, I.D.; Adiconis, X.; Fan, L.; Raychowdhury, R.; Zeng, Q.D.; et al. Full-length transcriptome assembly from RNA-Seq data without a reference genome. Nat. Biotechnol. 2011, 29, 644-652. [CrossRef]

63. Anders, S.; Huber, W. Differential expression analysis for sequence count data. Genome Biol. 2010, 11, R106. [CrossRef]

64. Young, M.D.; Wakefield, M.J.; Smyth, G.K.; Oshlack, A. Gene ontology analysis for RNA-seq: Accounting for selection bias. Genome Biol. 2010, 11, R14. [CrossRef] 
65. Mao, X.; Cai, T.; Olyarchuk, J.G.; Wei, L. Automated genome annotation and pathway identification using the KEGG Orthology (KO) as a controlled vocabulary. Bioinformatics 2005, 21, 3787-3793. [CrossRef]

66. Livak, K.J.; Schmittgen, T.D. Analysis of relative gene expression data using real-time quantitative PCR and the $2^{-\Delta \Delta C t}$ method. Methods 2001, 25, 402-408. [CrossRef]

67. Shannon, P.; Markiel, A.; Ozier, O.; Baliga, N.S.; Wang, J.T.; Ramage, D.; Amin, N.; Schwikowski, B.; Ideker, T. Cytoscape: A software environment for integrated models of biomolecular interaction networks. Genome Res. 2003, 13, 2498-2504. [CrossRef]

68. Cao, X.; Xu, C.; Zhang, Y.; Wei, H.; Liu, Y.; Cao, J.; Zhao, W.; Bao, K.; Wu, Q. Comparative transcriptome analysis of embryo invasion in the mink uterus. Placenta 2019, 75, 16-22. [CrossRef]

(C) 2019 by the authors. Licensee MDPI, Basel, Switzerland. This article is an open access article distributed under the terms and conditions of the Creative Commons Attribution (CC BY) license (http://creativecommons.org/licenses/by/4.0/). 